\title{
Evaluation of quality of life and photoplethysmography in patients with chronic venous insufficiency treated with foam sclerotherapy
}

\author{
Avaliação da qualidade de vida e fotopletismografia em pacientes com insuficiência \\ venosa crônica tratados através de escleroterapia com espuma
}

Felipe Coelho Neto ${ }^{1,2}$, Gilson Roberto Araújo², Iruena Moraes Kessler ${ }^{1}$

\begin{abstract}
Background: Ultrasound-guided foam sclerotherapy plays a major role in treatment of chronic venous insufficiency, providing clinical and hemodynamic improvement to patients undergoing treatment. Objectives: To examine the relationships between venous refilling time and impact of venous disease on quality of life and between changes in venous refilling time and improvement of symptoms after ultrasound-guided foam sclerotherapy for chronic venous insufficiency. Methods: Thirty-two patients classified as C4, C5 or C6 answered a questionnaire on quality of life and symptoms and their venous filling time was measured using photoplethysmography before and 45 days after treatment of chronic venous insufficiency with ultrasound-guided foam sclerotherapy. Results: Statistically significant improvements were observed in quality of life scores and in venous filling time and in the following symptoms: aching, heavy legs, restless legs, swelling, burning sensations, and throbbing $(p<0.0001)$. A similar improvement was also seen in the work and social domains of quality of life $(p<0.0001)$. Conclusions: As confirmed by questionnaire scores and venous refilling times, ultrasound-guided foam sclerotherapy demonstrated efficacy and resulted in high satisfaction levels and low rates of major complications.
\end{abstract}

Keywords: quality of life; chronic venous insufficiency; photoplethysmography; sclerotherapy; sclerosing solutions; color Doppler ultrasonography; varicose veins.

\begin{abstract}
Resumo
Contexto: A escleroterapia com espuma guiada por ultrassom (EGUS) ocupa lugar de destaque no tratamento da insuficiência venosa crônica (IVC), proporcionando melhora clínica e hemodinâmica aos pacientes submetidos ao tratamento. Objetivos: Verificar a correlação entre dados obtidos por questionário de qualidade de vida e de sintomas com dados obtidos por fotopletismografia (FPG), antes e depois do tratamento por escleroterapia com espuma guiada por ultrassom (EGUS) da insuficiência venosa crônica (IVC). Métodos: Um grupo de 32 pacientes, classificados como C4, C5 e C6, foi submetido à aplicação de questionário de qualidade de vida e sintomas, sendo aferido o tempo de enchimento venoso (TEV) por FPG antes e 45 dias depois do tratamento da IVC através de EGUS. O teste do sinal foi utilizado para análise estatística da melhora dos escores dos questionários e do TEV. O teste de McNemar foi utilizado para avaliação da melhora nos sintomas e do impacto do tratamento nas atividades laborais e sociais dos pacientes. Resultados: Houve melhora nos escores dos questionários de qualidade de vida e no TEV, com significância estatística ( $p<0,0001)$. Houve melhora estatisticamente significativa nos sintomas: dor, cansaço, edema, queimação, pernas inquietas e latejamento $(p<0,0001)$. Incremento na qualidade laboral e social após o tratamento apresentou melhora estatisticamente significativa $(p<0,0001)$. Não ocorreram complicações maiores ou efeitos adversos nesta série. Conclusões: A EGUS mostrou-se eficaz, com alto índice de satisfação e baixas taxas de complicacões maiores, ratificada pelos escores dos questionários e pelos TEVs aferidos pela FPG.
\end{abstract}

Palavras-chave: qualidade de vida; insuficiência venosa crônica; fotopletismografia; escleroterapia; soluções esclerosantes; ultrassonografia Doppler em cores; varizes.

\footnotetext{
'Universidade de Brasília - UnB, School of Medicine, Brasília, DF, Brazil.

${ }^{2}$ Hospital Regional da Asa Norte, Brasília, DF, Brazil.

Financial support: None.

Conflicts of interest: No conflicts of interest declared concerning the publication of this article.

Submitted: November 27, 2014. Accepted: January 14, 2015.
} 


\section{INTRODUCTION}

Chronic venous insufficiency (CVI) is a common disease in clinical practice. Its complications, especially venous stasis ulcers, cause significant morbidity, loss of functional mobility and reduced quality of life. ${ }^{1}$

The ideal treatment for primary varicose veins of lower limbs should be minimally invasive; repeatable whenever needed; free from significant complications; effective at eliminating reflux points; and of low cost; and should result in esthetic improvement while requiring little absence from work. ${ }^{2}$ Ultrasound-guided foam sclerotherapy (UGFS) is one option for the treatment of CVI that can meet these requirements. ${ }^{3}$

There are several studies of UGFS treatment for CVI reporting good clinical results and high rates of venous trunk occlusion assessed by vascular echography. ${ }^{4,5}$

However, few publications have confirmed the clinical results obtained with UGFS using objective parameters, such as the hemodynamic variations provoked by the treatment.

Quality of life questionnaires can be used as the parameters of subjective assessments of treatment efficacy. The Venous Insufficiency Epidemiological and Economic Study's Quality of Life/Symptom questionnaire (VEINES-QOL/Sym) consists of a self-report questionnaire addressing symptoms, their impact on daily activities and the psychological aspects of the disease. ${ }^{6}$ Higher scores indicate better outcomes. ${ }^{6,7}$

The hemodynamic variations provoked by treatment of CVI with UGFS can be determined by using photoplethysmography (PPG) to specifically measure venous refilling time (VRT). Venous refilling times obtained by PPG exhibit good correlations with direct measures of venous pressure. ${ }^{8-10}$ In turn, PPG is a rapid, non-invasive method suitable for outpatient settings that can provide quantitative and objective data to supplement the anatomical assessment and study of $\mathrm{CVI}^{11}$ both before and after therapeutic interventions. $^{12}$

In view of the above, this study aimed to evaluate the efficacy of treatment for CVI using UGFS, by correlating VRT values as measured by PPG with data obtained by administration of a questionnaire on quality of life and symptoms before and 45 days after treatment.

\section{METHODS}

An open prospective study was conducted to evaluate VRT, as assessed by digital PPG, and the scores obtained by administration of a questionnaire on quality of life and symptoms before and 45 days after treatment of varicose veins with UGFS. The study was carried out at the Vascular Surgery outpatients clinic at a public hospital in the city of Brasília, Federal District of Brazil, from December 2012 to August 2013

We selected patients over 18 years of age who presented with CVI of the lower limbs and were classified as $\mathrm{C} 4, \mathrm{C} 5$ or $\mathrm{C} 6$, according to the Clinical, Etiological, Anatomical, Pathophysiological (CEAP) classification. ${ }^{13}$ In order to obtain a homogenous sample, patients with deep venous thrombosis (DVT) identified by ultrasound examination were excluded from the study, as were patients with varicose veins but no involvement of the great or small saphenous vein. Cases of thrombophilia, active neoplasms or neoplasms in follow-up, reported lung disease, and peripheral artery insufficiency (ankle-arm index $<0.9$ ) were also excluded.

All patients signed a written consent form after being informed about the details of the study.

\section{Duplex ultrasound examination}

All examinations were performed in a standardized manner by the same physician (FCN) using a MyLab 40 ultrasound machine (Esaote ${ }^{\mathrm{TM}}$. Genoa, Italy) with a multifrequency 10-12 MHz transducer. Patients were placed in the standing position with their weight on the contralateral limb and the leg to be examined slightly rotated with the heel on the floor to relax the calf muscle while maintaining stability. The deep venous system was evaluated for DVT, and the superficial venous system was evaluated focusing on saphenofemoral and saphenopopliteal junctions, great and short saphenous veins, and on the presence of incompetent perforating veins. Reflux was induced with manual calf squeeze and was defined as reverse flow with duration longer than 0.5 seconds for saphenous vein and 0.35 seconds for perforating veins. ${ }^{14}$ Only perforating veins with diameters greater than $3.5 \mathrm{~mm}$ at the fascial level were considered for analysis, and reflux was recorded as described by Sandri et al. ${ }^{15}$

\section{Photoplethysmography}

A Hadeco PPG machine (Hayashi Denki CO. LTD, Kawasaki, Japan) was used to measure post-exercise VRT in the sitting position with the limb suspended, as described by Sam et al. ${ }^{16}$ Measurements were all taken at the same time of the day and in the same room. The PPG probe was attached to the skin using a sticky pad placed $13-39 \mathrm{~cm}$ above the medial malleolus and $1-2 \mathrm{~cm}$ posterior to the subcutaneous border of 
the tibia, in order to avoid areas with trophic changes resulting from CVI. With the patient as motionless as possible, the machine calibrated the signal, and once a stable baseline was achieved, the exercise was initiated. Patients completed 10 dorsal and plantar flexions over a 15 -second period and were then asked to remain at rest as motionless as possible.

The ejection of blood from the skin and the subsequent refilling curve were established and the machine calculated the venous filling curve. Three measurements were taken at intervals of 2-5 minutes, and the mean of all three measurements was used for analysis. Normal VRT was defined as $\geq 20$ seconds. Measurements of VRT were performed on the day of the first sclerotherapy session and repeated in each treated limb 45 days after the end of the treatment, with the probe placed at the same height as that used in the pretreatment examination.

\section{Quality of life and symptom questionnaire}

The Brazilian Portuguese version of the VEINESQOL/Sym questionnaire ${ }^{17}$ was administered in the form of an interview, which was performed by a single researcher $(\mathrm{FCN})$. The questionnaire was administered on the day of the first session and 45 days after the end of treatment.

\section{Sclerotherapy technique}

We have described the sclerotherapy technique elsewhere, ${ }^{18}$ focusing on the reflux pattern presented for each patient. When total occlusion of the target veins was not achieved in a single session, supplementary sessions were conducted, during which one or more punctures were performed, as required in each case, with 7-day intervals between sessions. The foam was produced by mixing 3\% polidocanol with ambient air at a ratio of $1: 4$, and the maximum total volume of foam injected in a single session was $10 \mathrm{~mL}$. Compression stockings (15-30 $\mathrm{mmHg}$ ) were prescribed to be worn day and night for 7 days, only removing them for the purposes of personal hygiene. From the 7 th day onwards, patients were recommended to wear stockings during the day only.

\section{Statistical analysis}

Non-parametric methods were applied using Microsoft Office Excel 2007 (Microsoft Corporation, Redmond, USA), SAS version 9.3 (SAS Institute Inc. Cary, USA), and R i386 3.0.1 (R Foundation for Statistical Computing, Vienna, Austria). The sign test was used to determine improvement in VRT and in VEINES-QOL/Sym scores. The McNemar test was performed to analyze improvement in symptoms.
The cutoff for statistical significance was set at less than or equal to $5 \%$.

\section{Research ethics}

The research project was submitted to and approved by the Research Ethics Committee (CAAE: 06791512.1.0000.5553). Additionally, all patients signed a written consent form after being informed about the details of the study.

\section{RESULTS}

Thirty-two patients were recruited. Females accounted for $82 \%(26 / 32)$ of the patients and mean age was 52 years (range 36-76 years). The left lower limb was the most frequently affected limb, representing $57 \%(18 / 32)$ of the sample. None of the patients had undergone previous invasive treatment at the point of enrollment on the study. Other epidemiological data are shown in Table 1.

Family history of DVT was present in four patients $(13 \%)$, and three $(10 \%)$ had a history of fracture and/or limb immobilization. Healed or active venous ulcers were present in $68 \%$ of the sample. The most frequent comorbidities were high blood pressure in eight individuals $(25 \%)$ and diabetes in four $(13 \%)$.

The patients' CEAP classifications broke down as follows: 10 (32\%) were classified as C4, seven (22\%) as $\mathrm{C} 5$, and $15(47 \%)$ as $\mathrm{C} 6$. All patients had a primary etiological classification. Anatomical classification was $62.5 \%$ for superficial veins and $37.5 \%$ for perforating veins. Reflux was the pathophysiology in all patients.

The mean number of punctures required per patient was $3.96(3-7)$, the mean number of sessions was $1.4(1-3)$ and the mean volume of foam per session was $8.5 \mathrm{~mL}(10-23 \mathrm{~mL})$.

There were five response options for questionnaire items referring to symptoms: "every day", "several times a week", "about once a week", "less than once a week", and "never". There was significant improvement in all items, as shown in Figure 1. For the purposes of statistical analysis, the responses "every day", "several times a week", and "about once a week"

Table 1. Epidemiological data.

\begin{tabular}{lcc}
\hline \multicolumn{1}{c}{ Variables } & Total & Percentage (\%) \\
\hline Previous DVT & 1 & 4 \\
Family history of DVT & 4 & 13 \\
Previous ulcer & 28 & 68 \\
High blood pressure & 8 & 25 \\
Diabetes mellitus & 4 & 13 \\
Fracture/immobilization & 3 & 10 \\
\hline
\end{tabular}

DVT: deep vein thrombosis. 


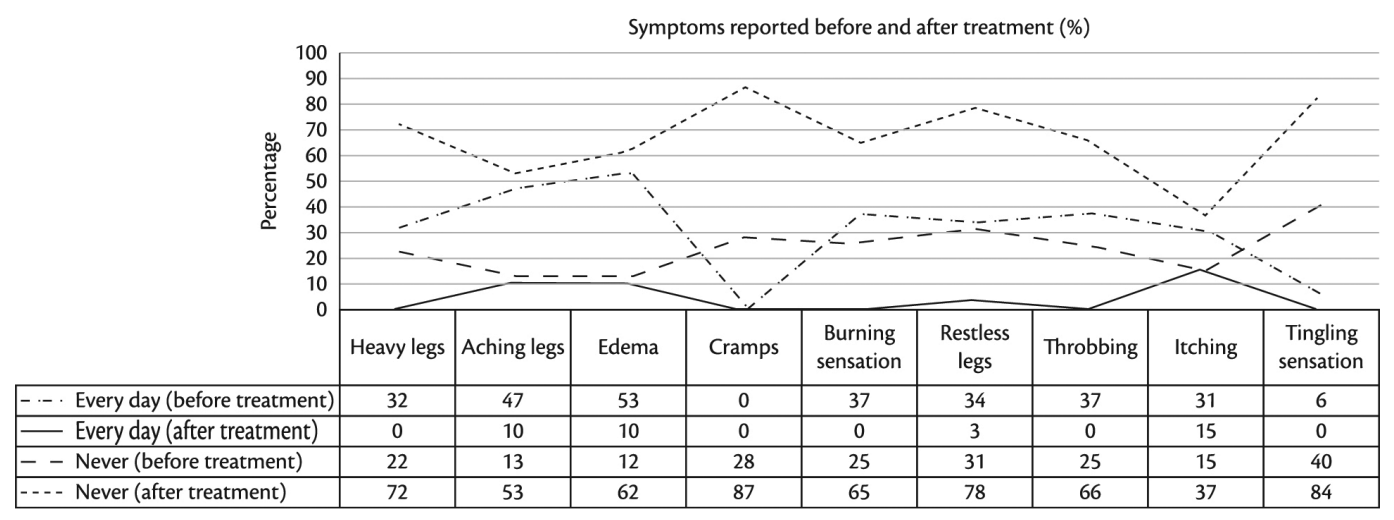

Figure 1. Improvement in symptoms.

were collapsed into a single category - group 1 - and the responses "less than once a week" and "never" were collapsed to form group 2. Group 1 responses were defined as indicating absence of improvement while group 2 responses represented improvements in the symptoms evaluated. All items exhibited statistical significance to $p<0.001$, except for the items "itching" and "tingling sensation". The $p$ values for improvements in symptoms are shown in Table 2.

Patients were also asked about the time of the day during which their leg problem was most severe. After treatment, $25 \%$ of the study population did not report any complaint during the entire day.

The next item on the questionnaire was: "Compared to one year ago, how would you rate your leg problem in general now?". Before treatment, 56\% of patients reported that the problem was somewhat worse or much worse than one year previously. After treatment, $100 \%$ of the patients reported that the problem was somewhat better or much better than one year previously.

Treatment resulted in improvement in patients' work activities and the percentage of patients who answered that the problem did not limit their work activities at all increased from $34 \%$ to $75 \%$. Additionally, none of the patients reported that the problem limited their activities a lot after treatment. When asked about limitations to daily household activities caused by their leg problem, $97 \%$ of patients answered that the problem did not cause any limitation to household activities. All items related to the impact of the disease on work or personal activities exhibited statistical significance to $\mathrm{p}<0.0001$, as shown in Table 3 .

There were improvements in activities performed both in standing and sitting positions, with the number of patients who answered that the problem did not limit these types of activity increasing from 34 to $94 \%$ and from 47 to $97 \%$ respectively.
Table 2. Improvement in symptoms after treatment with ultrasound-guided foam sclerotherapy.

\begin{tabular}{lc}
\hline \multicolumn{1}{c}{ Symptoms } & p-value \\
\hline Heavy legs & $<0.001$ \\
Aching legs & $<0.001$ \\
Swelling & $<0.001$ \\
Burning sensation & $<0.001$ \\
Restless legs & $<0.001$ \\
Throbbing & $<0.001$ \\
Itching & 0.146 \\
Tingling sensation & 0.1094 \\
\hline
\end{tabular}

Table 3. Improvement in work activities.

\begin{tabular}{ll}
\hline \multicolumn{1}{c}{ Work activities } & p-value \\
\hline Reduction in the amount of time spent at work & $<0.0001$ \\
Reduction in the amount of work accomplished & $<0.0001$ \\
Limitation in work time & $<0.0001$ \\
Difficulty in performing work & $<0.0001$ \\
\hline
\end{tabular}

These improvements attained statistical significance for both items $(p<0.01)$, as shown in Table 4 .

Patients who did not report any limitation to social activities with friends and family accounted for $94 \%$ of the sample after treatment $(p<0.01)$, in contrast with $37 \%$ of the sample before treatment. Before treatment, patients who answered that the problem interfered "extremely", "quite a bit" or "moderately" had accounted for $50 \%$ of the sample.

There was a specific item to assess the symptom "pain". Before treatment, $25 \%$ of patients had reported "very severe" or "severe" pain, whereas after treatment this figure was $12 \%$. Conversely, $19 \%$ of patients had reported "very mild" or "no" pain before treatment and this figure had risen to $56 \%$ after the procedure. Although the sample exhibited improvement in complaints of pain, these were not statistically significant $(\mathrm{p}>0.05)$. 
The psychological impact of leg problems on patients' daily lives was also analyzed. The percentage of patients who answered that they felt concerned about their appearance "all of the time" or "most of the time" decreased from $62 \%$ before treatment to

Table 4. Impact of the disease on personal activities.

\begin{tabular}{lc}
\hline \multicolumn{1}{c}{ Personal activities } & p-value \\
\hline Daily work activities & 0.002 \\
Daily household activities & $<0.001$ \\
Social or leisure activities performed in the standing & $<0.001$ \\
position & \\
$\begin{array}{l}\text { Social or leisure activities performed in the sitting } \\
\text { position }\end{array}$ & $<0.001$ \\
\hline
\end{tabular}

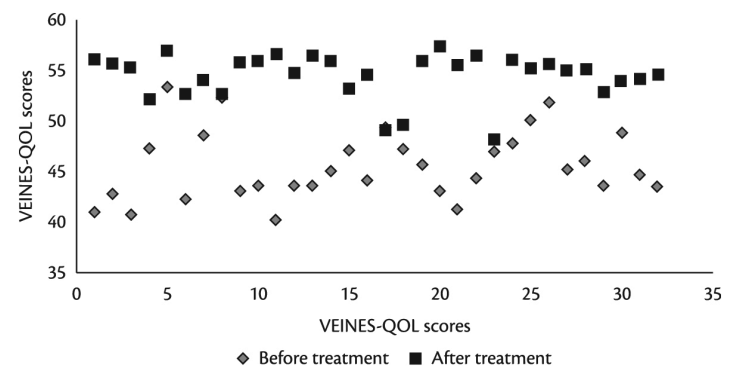

Figure 2. VRT values before and after treatment with UGFS. VRT: venous refilling time; UGFS: ultrasound-guided foam sclerotherapy.

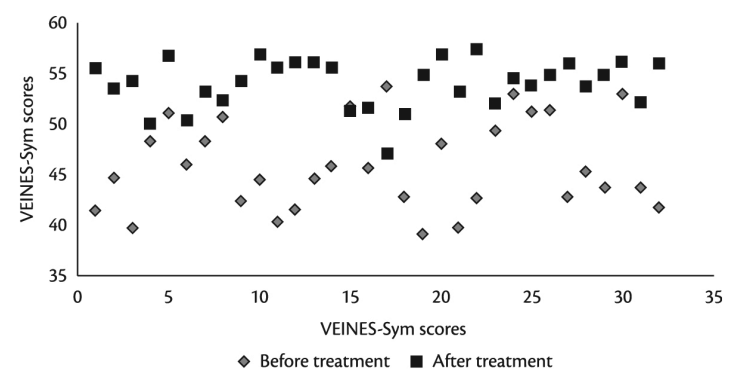

Figure 3. VEINES-QOL scores before and after treatment with UGFS. VEINES-QOL: Venous Insufficiency Epidemiological and Economic Study - Quality of Life; UGFS: ultrasound-guided foam sclerotherapy.

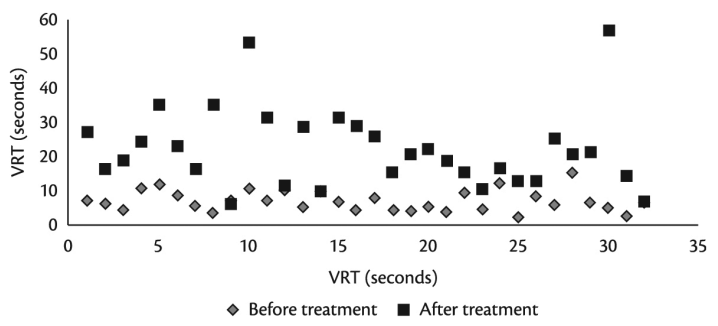

Figure 4. VEINES-Sym scores before and after treatment with UGFS. VEINES-Sym: Venous Insufficiency Epidemiological and Economic Study - Symptoms; UGFS: ultrasound-guided foam sclerotherapy.
$6 \%$ after treatment, while the percentage of those who reported feeling concerned about their appearance "a little of the time" or "none of the time" increased from $25 \%$ to $78 \%$ of the sample. After treatment, $87 \%$ of the patients reported feeling irritated "none of the time". Half of the patients did not feel they were a burden to their family and friends before treatment and this figure had increased to $100 \%$ after treatment. Initially, $60 \%$ of the patients were worried about bumping into things "all of the time". After intervention, this value had fallen to $6 \%$. Additionally, before UGFS $72 \%$ of patients had answered that the appearance of their legs influenced their choice of clothing "all of the time" and this percentage had decreased to $22 \%$ after the procedure.

The mean result for VRT before treatment was 6.7 seconds (2.0-15.3 seconds) and after treatment mean VRT was 22.2 seconds (6.0-53.2 seconds), which is an increase of more than $230 \%$.

Before treatment, the mean VEINES-QOL score was 44.8 (40.2-53.4), and the mean VEINES- Sym score was 45.03 (39.1-53.1). After treatment, the mean VEINES-QOL and VEINES- Sym scores were 54.6 (48.2-57.3) and 54.1 (47.1-57.6) respectively.

Figure 2 compares VRT values before and after treatment, and Figures 3 and 4 show before and after results for VEINES-QOL and VEINES-Sym scores respectively. Statistically significant improvements $(p<0.0001)$ were observed in VRT values and in both questionnaire scores after treatment.

There were no major complications such as DVT or pulmonary embolism during follow-up. Phlebitis $(19 \%)$, local pain $(90 \%)$, pigmentation $(97 \%)$, and local induration (97\%) were the most frequent minor complications.

Seven (47\%) of the patients classified as C6 exhibited healed ulcers at 45 days after treatment. There were no cases of ulcer recurrence in the $\mathrm{C} 5$ group.

\section{DISCUSSION}

Over the last decade, alternative treatments for CVI such as endovenous thermal ablation and UGFS have become popular. These are outpatient procedures performed with local tumescent anesthesia that do not require hospitalization or absence from daily activities and several studies have demonstrated that they are safe and effective for eliminating venous reflux. ${ }^{19-22}$ Furthermore, the clinical impact of these treatments can be measured by quality of life questionnaires, whether specific ${ }^{14,23}$ or generic. ${ }^{24}$

Ambulatory venous pressure is considered the best parameter for evaluation of hemodynamic 
improvement after treatment, but it is an invasive method with limited applications in routine practice. ${ }^{25}$ Air plethysmography is an effective alternative for measuring CVI severity, ${ }^{26}$ but it is a long test that requires a large instrument. ${ }^{2}$ In turn, VRT as measured by PPG offers good reproducibility and good correlation with direct measures of venous pressure. ${ }^{9}$ Moreover, it is a rapid test performed with a portable device and can be widely used in clinical practice.

Our data consistently demonstrated that there was an improvement in symptoms after treatment and confirm findings reported by Bradbury et al. ${ }^{11}$ The portion of the questionnaire related to symptoms (VEINES-Sym) identified improvements in all nine items 45 days after treatment, with statistical significance for the following items: pain, heavy legs, swelling, burning sensation, restless legs, and throbbing $(\mathrm{p}<0.0001)$. The portion of the questionnaire related to quality of life (VEINES-QOL) confirmed these data, since it showed that $100 \%$ of patients reported being somewhat better $(6 \%)$ or much better $(94 \%)$ than one year before treatment. There were statistically significant improvements in the ability to perform both work and household activities, with $75 \%$ of patients reporting no limitation to work activities and $97 \%$ of patients reporting no difficulty in performing their usual household activities or social activities with friends and/or family.

We would like to draw attention to the improvement in pain, evidenced by the increase from 25 to $56 \%$ in the percentage of patients with no pain or complaining of very mild pain. Although analysis of this data did not reveal statistical significance, this improvement confirms findings previously reported in the literature. ${ }^{27}$ The analysis of patients' psychological profiles also revealed improvements in all questionnaire items. The instrument is therefore an important tool for evaluating treatment outcomes, since patients have usually been dealing with CVI for a long time, often relying on palliative treatments that have failed to achieve definitive resolution of the disease. ${ }^{28}$

There were no thromboembolic events or adverse effects resulting from sclerotherapy in this series of patients. Conversely, local complications were observed, including pigmentation, induration, and pain in the varicosities treated. These complications did not cause severe clinical repercussions, as confirmed by the high rate of patient satisfaction observed in the responses to the VEINES-QOL. Our data reveal higher local complication rates after UGFS than reported in other publications..$^{29,30}$ Notwithstanding, the majority of patients in those studies were classified as CEAP 2-3, which means less severe clinical CVI status. It is believed that the higher rate of complications found in this study is the result of actively searching for information and the fact that most of our cases presented thicker varicose veins (CEAP 5 and 6).

Mean VRT as measured by PPG increased from 6.7 before treatment to 22.2 after treatment $(\mathrm{p}<0.0001)$. This finding had a statistically significant direct relationship with the increase in VEINESQOL/Sym scores, which confirms that VRT may have applications as an objective marker of short term clinical improvement in patients who have had UGFS treatment. As demonstrated by Kulkarni et al., ${ }^{12}$ VRT may be an effective marker of venous ulcer recurrence when it does not improve after treatment. There were no cases of deep venous reflux in the sample. Therefore, the lack of improvement in VRT exhibited by patients can be explained by calf pump failure or restriction of ankle mobility as a result of trophic skin changes. In our experience, the improvement in VRT was associated with a rate of ulcer healing of $47 \%$ in patients classified as $\mathrm{C} 6,45$ days after treatment with UGFS. The sample size and the limited follow-up time are weaknesses of our study.

However, the VEINES QOL/Sym questionnaire has never been used before to assess the results of CVI treatment using UGFS. The VEINES-QOL/Sym was the only questionnaire available that had been translated and adapted for use with the Brazilian population at the start of this study. Although other more specific questionnaires for venous ulcers exist, such as the Charing Cross Venous Ulcer Questionnaire, ${ }^{31}$ they were not available for use at the start of our research project.

This study is the first report of use of this questionnaire for this purpose and shows that the VEINES QOL/Sym questionnaire is a feasible tool that exhibited a direct relationship with the objective hemodynamic measure obtained by PPG, in addition to portraying the psychological impact of the treatment on quality of life in the short-term.

In turn, UGFS proved to be effective and resulted in high levels of satisfaction and low rates of major complications, confirmed by the VEINES QOL/Sym scores and by VRT as measured by PPG.

Further studies are needed to evaluate medium-term and long-term results in order to analyze whether the results we obtained will be maintained and whether patients will still be free of symptoms and will exhibit sustained hemodynamic improvement after longer follow-up. 


\section{ACKNOWLEDGEMENT}

The authors are grateful to Beatriz Helena Pavan Balducci Coelho, Olympio Teixeira, Sirleide Braga, and Rosana Falasque for their dedication and valuable advice during the execution of this project.

\section{REFERENCES}

1. Silva MC. Chronic venous insufficiency of the lower limbs and its socio-economic significance. Int Angiol. 1991;10(3):152-7. PMid:1765717.

2. Guex JJ, Isaacs MN. Comparison of surgery and ultrasound guided sclerotherapy for treatment of saphenous varicose veins: must the criteria for assessment be the same? Int Angiol. 2000;19(4):299302. PMid: 11305726.

3. Wright $\mathrm{D}$, Gobin JP, Bradbury AW, et al. Varisolve ${ }^{\bullet}$ polidocanol microfoam compared with surgery or sclerotherapy in the management of varicose veins in the presence of trunk vein incompetence: European randomized controlled trial. Phlebology. 2006;21(4):180-90. http://dx.doi.org/10.1258/026835506779115807.

4. Orsini $C$, Brotto $M$. Immediate pathologic effects on the vein wall of foam sclerotherapy. Dermatol Surg. 2007;33(10):1250-4. PMid:17903159.

5. Figueiredo M, Araújo SP, Penha-Silva N. Microfoam ultrasoundguided sclerotherapy in primary trunk varicose veins. J Vasc Bras. 2006;5(3):177-83. http://dx.doi.org/10.1590/S1677-54492006000300005.

6. Lamping DL, Schroter S, Kurz X, Kahn SR, Abenhaim L. Evaluation of outcomes in chronic venous disorders of the leg: development of a scientifically rigorous, patient-reported measure of symptoms and quality of life. J Vasc Surg. 2003;37(2):410-9. http://dx.doi. org/10.1067/mva.2003.152. PMid:12563215

7. Kahn SR, Lamping DL, Ducruet T, et al. VEINES-QOL/Sym questionnaire was a reliable and valid disease-specific quality of life measure for deep venous thrombosis. J Clin Epidemiol. 2006;59(10): 1056.e1-1056.e4. http://dx.doi.org/10.1016/j.jclinepi.2005.10.016. PMid:16980144.

8. Rosfors S. Venous photoplethysmography: relationship between transducer position and regional distribution of venous insufficiency. J Vasc Surg. 1990;11(3):436-40. http://dx.doi.org/10.1016/07415214(90)90244-5. PMid:2313832.

9. Abramowitz HB, Queral LA, Finn WR, et al. The use of photoplethysmography in the assessment of venous insufficiency: a comparison to venous pressure measurements. Surgery. 1979;86(3):434-41. PMid:473029.

10. Nicolaides AN, Miles C. Photoplethysmography in the assessment of venous insufficiency. J Vasc Surg. 1987;5(3):405-12. http://dx.doi. org/10.1016/0741-5214(87)90047-4. PMid:3334678.

11. Bradbury AW, Bate G, Pang K, Darvall KA, Adam DJ. Ultrasoundguided foam sclerotherapy is a safe and clinically effective treatment for superficial venous reflux. J Vasc Surg. 2010;52(4):939-45. PMid:20638224.

12. Kulkarni SR, Barwell JR, Gohel MS, Bulbulia RA, Whyman MR, Poskitt KR. Residual venous reflux after superficial venous surgery does not predict ulcer recurrence. Eur J Vasc Endovasc Surg. 2007;34(1):107-11. http://dx.doi.org/10.1016/j.ejvs.2006.12.033. PMid:17408990.

13. Eklöf B, Rutherford RB, Bergan JJ, et al. Revision of the CEAP classification for chronic venous disorders: consensus statement. J Vasc Surg. 2004;40(6):1248-52. http://dx.doi.org/10.1016/j. jvs.2004.09.027. PMid:15622385.
14. Labropoulos N, Tiongson J, Pryor L, et al. Definition of venous reflux in lower-extremity veins. J Vasc Surg. 2003;38(4):793-8. http://dx.doi.org/10.1016/S0741-5214(03)00424-5. PMid:14560232.

15. Sandri JL, Barros FS, Pontes S, Jacques C, Salles-Cunha SX. Diameterreflux relationship in perforating veins of patients with varicose veins. J Vasc Surg. 1999;30(5):867-74. http://dx.doi.org/10.1016/ S0741-5214(99)70011-X. PMid:10550184.

16. Sam RC, Darvall KA, Adam DJ, Silverman SH, Bradbury AW. Digital venous photoplethysmography in the seated position is a reproducible noninvasive measure of lower limb venous function in patients with isolated superficial venous reflux. J Vasc Surg. 2006;43(2):335-41. http://dx.doi.org/10.1016/j.jvs.2005.10.039. PMid:16476612.

17. Moura RMF, Gonçalves GS, Navarro TP, Britto RR, Dias RC. Transcultural adaptation of VEINES/QOL-Sym questionnaire: evaluation of quality of life and symptoms in chronic venous disease. J Vasc Bras. 2011;10(1):17-23. http://dx.doi.org/10.1590/ S1677-54492011000100004.

18. Coelho F No, Araujo GR, Kessler IM, Amorim RF, Falcao DP. Treatment of severe chronic venous insufficiency with ultrasound-guided foam sclerotherapy: a two-year series in a single center in Brazil. Phlebology. 2015;30(2):113-8. http://dx.doi.org/10.1177/0268355513517225. PMid:24335090.

19. Darwood RJ, Gough MJ. Endovenous laser treatment for uncomplicated varicose veins. Phlebology. 2009;24(Suppl 1):50-61. http://dx.doi.org/10.1258/phleb.2009.09s006. PMid:19307441.

20. Gohel MS, Davies AH. Radiofrequency ablation for uncomplicated varicose veins. Phlebology. 2009;24(Suppl 1):42-9. http://dx.doi. org/10.1258/phleb.2009.09s005. PMid:19307440.

21. Smith PC. Foam and liquid sclerotherapy for varicose veins. Phlebology. 2009;24(Suppl 1):62-72. http://dx.doi.org/10.1258/ phleb.2009.09s007. PMid:19307442.

22. Proebstle TM, Vago B, Alm J, Göckeritz O, Lebard C, Pichot O. Treatment of the incompetent great saphenous vein by endovenous radiofrequency powered segmental thermal ablation: first clinical experience. J Vasc Surg. 2008;47(1):151.e1-6.e1. http://dx.doi. org/10.1016/j.jvs.2007.08.056. PMid:18178468.

23. Garratt AM, Macdonald LM, Ruta DA, Russell IT, Buckingham JK, Krukowski ZH. Towards measurement of outcome for patients with varicose veins. Qual Health Care. 1993;2(1):5-10. PMid:10132081.

24. Smith JJ, Garratt AM, Guest M, Greenhalgh RM, Davies AH Evaluating and improving health-related quality of life in patients with varicose veins. J Vasc Surg. 1999;30(4):710-9. http://dx.doi. org/10.1016/S0741-5214(99)70110-2. PMid:10514210.

25. Nicolaides AN. Cardiovascular Disease Educational and Research Trust, European Society of Vascular Surgery, The International Angiology Scientific Activity Congress Organization, International Union of Angiology, Union Internationale de Phlebologie at the Abbaye des Vaux de Cernay. Investigation of chronic venous insufficiency: a consensus statement (France, March 5-9, 1997). Circulation. 2000;102(20): E126-63.

26. Engelhorn CA, Beffa CV, Bochi G, et al. Can air plethysmography evaluate the severity of chronic venous insufficiency?.J Vasc Bras. 2004;3:311-6.

27. Rasmussen LH, Lawaetz M, Bjoern L, Vennits B, Blemings A, Eklof B. Randomized clinical trial comparing endovenous laser ablation, radiofrequency ablation, foam sclerotherapy and surgical stripping for great saphenous varicose veins. Br J Surg. 2011;98(8):1079-87. http://dx.doi.org/10.1002/bjs.7555. PMid:21725957.

28. Ruckley CV. Socioeconomic impact of chronic venous insufficiency and leg ulcers. Angiology. 1997;48(1):67-9. http://dx.doi. org/10.1177/000331979704800111. PMid:8995346. 
29. Cavezzi A, Parsi K. Complications of foam sclerotherapy. Phlebology. 2012;27(Suppl 1):46-51. http://dx.doi.org/10.1258/ phleb.2012.012S09. PMid:22312067.

30. Jia X, Mowatt G, Burr JM, Cassar K, Cook J, Fraser C. Systematic review of foam sclerotherapy for varicose veins. Br J Surg. 2007;94(8):92536. http://dx.doi.org/10.1002/bjs.5891. PMid:17636511.

31. Couto RC, Leal FJ, Pitta GBB, Bezerra RCB, Segundo Walmir SS, Porto TM. Tradução e adaptação cultural do Charing Cross Venous Ulcer Questionnaire - Brasil. J Vasc Bras. 2012;11(2):102-7. http:// dx.doi.org/10.1590/S1677-54492012000200006.
Correspondence Felipe Coelho Neto AngioClínica Brasília SEPS 709/909, Centro Médico Julio Adnet, Salas 419-422, Bloco A

CEP 70100-360 - Brasília (DF), Brazi Tel: +55 (61) 3328-1940

E-mail:contato@drfelipecoelho.com.br

Author information

FCN - vascular surgeon at the Vascular Surgery Unit, Hospital Regional da Asa; MSc in Medical Sciences from Universidade de Brasília (UnB)

IMK - MSc and PhD in Medical Sciences from Universidade de Brasília (UnB).

GRA - vascular surgeon at the Vascular Surgery Unit, Hospital Regional da Asa Norte.

Author contributions Conception and design: FCN Analysis and interpretation: FCN, GRA Data collection: FCN Writing the article: FCN, IMK Critical revision of the article: FCN, IMK Final approval of the article*: FCN, GRA, IMK Statistical analysis: $F C N$

Overall responsibility: FCN

*All authors have read and approved of the final version of the article submitted to I Vasc Bras. 